\title{
Phacoemulsification in posterior polar cataract
}

\section{Facoemulsificação na catarata polar posterior}

\author{
Servet Cetinkaya ${ }^{1}$, Yasemin Fatma Cetinkaya² ${ }^{2}$ Zeynep Dadaci ${ }^{3}$, Nursen Oncel Acir ${ }^{3}$
}

\section{ABSTRACT}

Purpose: To evaluate the results and complications of phacoemulsification surgery in eyes with posterior polar cataracts and compare the techniques of viscodissection and hydrodissection.

Methods: The medical records of 29 consecutive patients (16 males, 13 females) with posterior polar cataracts (44 eyes) who had undergone cataract surgery were retrospectively reviewed. Patients were divided into two groups according to the technique used; viscodissection was applied to the experimental group (group 1) and hydrodissection to the control group (group 2).

Results: The postoperative best corrected visual acuity (BCVA) was $0.19 \pm 0.22$ $\log$ MAR (mean \pm standard deviation) (range 0.00-0.70) in group 1 and $0.25 \pm 0.18$ logMAR (range 0.00-0.70) in group 2. Although the mean postoperative BCVA in group 1 was greater than that in group 2, the difference was not statistically significant $(p=0.165)$. The mean postoperative BCVA was significantly greater than the mean preoperative BCVA in both groups $(p=0.00)$. Intraoperatively, posterior capsular rupture occurred during the removal of the cortex in three eyes (13\%) of group 1 patients, with vitreous loss and anterior vitrectomy in one eye only. In group 2, six eyes (28.5\%) presented posterior capsular rupture, and anterior vitrectomy was performed because of vitreous loss in three eyes. Although the percentage of posterior capsular rupture was greater in group 2, the difference was not statistically significant $(p=0.207)$

Conclusions: Complications in posterior polar cataract surgeries can be overcome by being careful throughout the surgery and using proper techniques. Viscodissection may be better for avoiding posterior capsular rupture than hydrodissection.

Keywords: Phacoemulsification/methods; Vitreous body/surgery; Dissection/ methods; Visual acuity

\section{RESUMO}

Objetivo: Avaliar os resultados e complicações da cirurgia de facoemulsificação em olhos com catarata polar posterior e comparar as técnicas de viscodissecção e hidrodissecção.

Métodos: Os prontuários de 29 pacientes consecutivos (16 homens, 13 mulheres) com posterior cataratas polares (44 olhos), que haviam sido submetidos a cirurgia de catarata foram analisados retrospectivamente. Os pacientes foram divididos em dois grupos de acordo com a técnica utilizada; viscodissecção foi aplicada ao grupo experimental (grupo 1) e hidrodissecção para o grupo de controle (grupo 2). Resultados: No pós-operatório, a melhor acuidade visual corrigida (BCVA) foi 0,19 $\pm 0,22$ logMAR (média \pm desvio padrão) (variação 0,00-0,70) no grupo 1 e $0,25 \pm 0,18(0,00-0,70)$ logMAR no grupo 2. Embora a média da BCVA pós-operatória do grupo 1 tenha sido maior do que a do grupo 2, a diferença não foi estatisticamente significativa $(p=0,165)$. A melhor acuidade visual corrigida pós-operatória foi significativamente melhor do que no pré-operatório, em ambos os grupos $(p=0,00)$. No grupo 1, houve ruptura capsular posterior durante a remoção do córtex em três olhos (13\%); houve perda vítrea e necessidade de vitrectomia anterior mas apenas em destes olhos. No grupo 2, a ruptura da cápsula posterior ocorreu em seis olhos (28,5\%); vitrectomia anterior foi necessária após a perda vítrea em três destes olhos. Embora a porcentagem de ruptura da cápsula posterior tenha sido maior no grupo 2, a diferença não foi estatisticamente significativa $(p=0,207)$.

Conclusões: As complicações em cirurgias de catarata polar posterior podem ser superadas com cautela durante toda a cirurgia e usando técnicas adequadas. Viscodissecção é melhor para evitar a posterior ruptura capsular do que hidrodissecção.

Descritores: Facoemulsificação/métodos; Corpo vítreo/cirurgia; Dissecação/métodos; Acuidade visual

\section{INTRODUCTION}

Posterior polar cataracts are white, well-demarcated, disc-shaped opacities located on the central posterior capsule and are a form of congenital cataract with autosomal dominant inheritance ${ }^{(1,2)}$.

Posterior polar cataract surgery is difficult for surgeons to perform because of the high risk of posterior capsular rupture, which itself stems from the opacity's adherence to the capsule and the extreme thinness and fragility of the posterior capsule $e^{(3-7)}$.

In the present study, we evaluated the results and complications of phacoemulsification surgery in eyes with posterior polar cataracts and compared the techniques of viscodissection and hydrodissection.

\section{METHODS}

The study protocol was approved by the local ethics committee (Selcuk University Faculty of Medicine; \# 2014/206). Informed consent was obtained from the patients for the cataract surgery. The study was carried out according to the tenets of the Declaration of Helsinki.

In the present study, we retrospectively evaluated 44 eyes with posterior polar cataracts in 29 consecutive patients that had been operated upon between February 2006 and September 2010. Each patient underwent a complete ophthalmologic examination, including tests for uncorrected visual acuity, best corrected visual acuity (BCVA), and intraocular pressure (IOP), as well as slit-lamp biomicroscopy and fundus examinations, both preoperatively and postoperatively. The SRK II formula was used for the calculation of the intraocular lens (IOL) power.

Patients in our study were divided into two groups according to the technique used: viscodissection was applied to the experimental group (group 1) and hydrodissection to the control group (group 2). No patient showed any other related ocular pathologies or systemic disorders, and nuclei in all eyes were soft.
Submitted for publication: June 8, 2015

Accepted for publication: March 16, 2016

Ophthalmology Clinics, Turkish Red Crescent Hospital, Konya, Turkey.

2 Ophthalmology Clinics, Ataturk Training and Research Hospital, Ankara, Turkey.

${ }^{3}$ Department of Ophthalmology, Mevlana University, Faculty of Medicine, Konya, Turkey.
Funding: No specific financial support was available for this study.

Disclosure of potential conflicts of interest: None of the authors have any potential conflict of interest to disclose.

Corresponding author: Servet Cetinkaya. Turkish Red Crescent Hospital (Kizilay Hastanesi), Ophthalmology Clinics, Sukran Mh. Taskapu Medrese Sok. No:15 - Meram, 42200 - Konya - Turkey E-mail: drservet42@gmail.com

Approved by the following research ethics committee: Selcuk University Faculty of Medicine (\#2014/206). 
All operations were performed by a single surgeon (SC). With each patient under sub-Tenon anesthesia, a 2.8-mm clear corneal incision was made with a steel blade superotemporally, after which the anterior chamber was filled with a dispersive viscoelastic material (2\% hydroxypropyl methylcellulose; Easy Visc; OphthalMed; Grebenau, Germany). After continuous curvilinear capsulorhexis, hydrodelineation was performed. Viscodissection was performed on the patients in group 1, meaning that a dispersive viscoelastic material was injected into the capsule to separate the lens from the capsule and make it freely mobile. Hydrodissection was performed on the patients in group 2; then a side-port entrance was made with a 19-gauge microvitreoretinal (MVR) knife. To emulsify the nucleus, the infusion bottle was lowered to $50 \mathrm{~cm}$, and low power (35\%), a low vacuum $(200 \mathrm{mmHg})$, and a low aspiration rate $(20 \mathrm{cc} / \mathrm{min})$ were used to minimize the stress on the posterior capsule (Sovereign Compact Phacoemulsification System; Abbott Medical Optics, Santa Ana, CA, USA). Both the aspiration of the cortex and polishing were performed from the periphery to the center, and cortex removal of the central portion was avoided even if it was not open due to the risk of capsular rupture. The capsular bag was filled with a cohesive viscoelastic material (1.6\% Sodium Hyaluronate; EasyLuron; OphthalMed; Grebenau, Germany). A foldable monofocal posterior chamber IOL (Acriva; VSY Biotechnology, Amsterdam, Netherlands) was implanted into the capsular bag. After surgery, the patients received topical antibiotics four times a day and topical steroids six times a day for 1 week; the use of topical steroids was then tapered over the subsequent 3 weeks. Postoperatively, the patients were routinely examined on the first day and after the first week, first month, third month, sixth month, first year, and second year. For the statistical analysis, the postoperative values from the first month were used.

Statistical software (SPSS version 22; IBM Corporation, Armonk, NY, USA) was used for the data analysis. Data were compared using the chi-square test, Mann-Whitney $U$ test, and Wilcoxon signed-rank test. For all statistical tests, $p<0.05$ was accepted as statistically significant.

\section{RESULTS}

Group 1 included 15 patients, of whom eight (53.3\%) were male and seven (46.7\%) were female. Eight patients (53.3\%) had bilateral cataracts, whereas seven (46.7\%) had a unilateral cataract. Their mean age was $40.52 \pm 15.63$ ( \pm SD) (range 22-74) years, and the mean follow-up time was $21.91 \pm 9.58$ (8-36) months. Group 2 consisted of 14 patients, of whom eight (57.2\%) were male and six (42.8\%) were female. Seven patients (50\%) had bilateral cataracts, and seven (50\%) had a unilateral cataract. Their mean age was $44.66 \pm 15.87$ (24-71) years, and the mean follow-up time was $22.14 \pm 8.44$ (9-36) months. No statistically significant differences were found between the groups in terms of age, sex, laterality, and follow-up time $(p=0.329$, $p=0.744, p=0.894$, and $p=0.962$, respectively). In group 1 , the size of the polar opacities was smaller than $4 \mathrm{~mm}$ in 18 eyes (78.2\%) and larger than $4 \mathrm{~mm}$ in 5 eyes (21.8\%). In group 2, it was smaller than $4 \mathrm{~mm}$ in 16 eyes (76.2\%) and larger than $4 \mathrm{~mm}$ in 5 eyes $(23.8 \%)(p=0.871)$. We did not detect any eyes with preexisting posterior capsule dehiscence in either of the groups preoperatively.

The mean preoperative BCVA was $0.69 \pm 0.25$ (0.30-1.00) logMAR in group 1 and $0.64 \pm 0.23(0.40-1.00) \log M A R$ in group $2(p=0.489)$. The mean postoperative BCVA was $0.19 \pm 0.22$ (0.00-0.70) logMAR in group 1 and $0.25 \pm 0.18(0.00-0.70) \log M A R$ in group 2. Although the mean postoperative BCVA in group 1 was greater than that in group 2 , the difference was not statistically significant ( $p=0.165)$. The mean postoperative BCVA was significantly greater than the mean preoperative BCVA in both groups $(p=0.00)$. The mean preoperative IOP was $14.47 \pm 2.59(10-19) \mathrm{mmHg}$ in group 1 and $14.90 \pm 2.64$ (10-19) $\mathrm{mmHg}$ in group $2(p=0.595)$. The mean postoperative IOP was $14.34 \pm 2.28(11-18) \mathrm{mmHg}$ in group 1 and $14.66 \pm 2.51(10-19) \mathrm{mmHg}$ in group $2(p=0.670)$.
Intraoperatively, posterior capsular rupture occurred during the removal of the cortex in three eyes (13\%) in the group 1 patients, but vitreous loss requiring anterior vitrectomy occurred in only one eye; no rupture occurred during viscodissection in this group. Conversely, posterior capsular rupture occurred in six eyes (28.5\%) in the group 2 patients; four of them occurred during hydrodissection, and two of them occurred during the removal of the cortex. Vitreous loss requiring anterior vitrectomy occurred in three eyes. Although the percentage of posterior capsular rupture was greater in group 2, the difference was not statistically significant ( $p=0.207$ ). A polymethyl methacrylate sulcus fixation IOL was implanted in one eye (4.3\%) in group 1 and in three eyes (14.2\%) in group 2 ( $p=0.258$ ). No postoperative problems were observed in these eyes. In-the-bag IOLs were implanted in five other eyes due to relatively smaller ruptures. Capsular ruptures did not affect the outcomes. In eight eyes (34.7\%) in group 1 and seven eyes (33.3\%) in group 2, total polar opacities could not be cleared during surgery because of firm adherence of the opacity to the posterior capsule forming a plaque $(p=0.920)$. $\mathrm{Nd}$ :YAG laser capsulotomy was performed on these eyes after the third month postoperatively to prevent inflammation.

The visual outcomes were not satisfactory in two eyes (8.6\%) in group 1 because of age-related macular degeneration, as well as in two eyes (9.5\%) in group 2, with one resulting from age-related macular degeneration and the other from diabetic retinopathy $(p=0.925)$. This age-related macular degeneration and diabetic retinopathy could not be detected preoperatively because of poor visualization of the fundus. In four eyes (17.3\%) in group 1 and three eyes (14.2\%) in group 2, postoperative vision was unsatisfactory because of preexisting amblyopia in patients with unilateral cataracts $(p=0.781)$. Four patients (26.6\%) in group 1 and four patients (28.5\%) in group 2 had a family history of congenital cataracts $(p=0.888)$. The demographic characteristics and preoperative findings of the patients are summarized in table 1. Intraoperative and postoperative findings of the patients are summarized in table 2 .

\section{DISCUSSION}

Posterior capsule rupture risk during surgery is exceptionally high in posterior polar cataracts compared with other types of cataracts $(5-8,19,20)$. The incidence of posterior capsule rupture has been reported to be between $26 \%$ and $36 \%{ }^{(4)}$. In our study, this ratio was $13 \%$ in group 1 and $28.5 \%$ in group 2.

Many techniques have been described to avoid complications and minimize this risk. Using viscodissection instead of hydrodissection may protect the posterior capsule at the beginning of the surgery $^{(9-11)}$. In our study, we used the viscodissection technique in the group 1 patients, which involved the injection of a dispersive viscoelastic material into the capsule to separate the lens from the capsule and make it freely mobile. We used the hydrodissection technique in the group 2 (control group) patients. No posterior capsular rupture occurred during viscodissection; however, four ruptures occurred during hydrodissection. The other ruptures occurred during the removal of the cortex in both groups. Although the percentage of posterior capsular rupture was greater in group 2, this difference was not statistically significant. The mean postoperative BCVA in group 1 was greater than that in group 2, although the difference was not statistically significant. Overfilling the anterior chamber with viscoelastic material should be avoided, the bottle height should be lowered, and the power, vacuum, and flow rate should be decreased to avoid surging and overpressurization of the anterior chamber. Removal of the cortex and polishing of the capsule should be started from the periphery toward the center. Moreover, if there is a posterior plaque firmly adherent to the capsule, postoperative Nd:YAG laser capsulotomy should be performed ${ }^{(12-14)}$.

Hayashi et al. ${ }^{(1)}$ reported good results using pars plana lensectomy with IOL implantation on the remaining anterior capsule when 
Table 1. The demographic characteristics and preoperative findings of the patients

\begin{tabular}{|c|c|c|c|}
\hline & Group 1 (viscodissection group) & Group 2 (hydrodissection group) & $p$ value \\
\hline Age (years) & $40.52 \pm 15.63(22-74)$ & $44.66 \pm 15.87(24-71)$ & 0.329 \\
\hline Sex & & & 0.744 \\
\hline Male & $8(53.3 \%)$ & $8(57.2 \%)$ & \\
\hline Female & $7(46.7 \%)$ & $6(42.8 \%)$ & \\
\hline Laterality & & & 0.894 \\
\hline Unilateral & $7(46.7 \%)$ & $7(50.0 \%)$ & \\
\hline Bilateral & $8(53.3 \%)$ & $7(50.0 \%)$ & \\
\hline Follow-up time (months) & $21.91 \pm 9.58(8-36)$ & $22.14 \pm 8.44(9-36)$ & 0.962 \\
\hline Preoperative BCVA (logMAR) & $0.69 \pm 0.25(0.30-1.00)$ & $0.64 \pm 0.23(0.40-1.00)$ & 0.489 \\
\hline Preoperative IOP (mmHg) & $14.47 \pm 2.59(10-19)$ & $14.90 \pm 2.64(10-19)$ & 0.595 \\
\hline Size of polar opacity & & & 0.871 \\
\hline$<4 \mathrm{~mm}$ (eyes) & $18(78.2 \%)$ & $16(76.2 \%)$ & \\
\hline$>4 \mathrm{~mm}$ (eyes) & $5(21.8 \%)$ & $5(23.8 \%)$ & \\
\hline Presence of retinal diseases (ARMD, DR) (eyes) & $2(8.6 \%)$ & $2(9.5 \%)$ & 0.925 \\
\hline History of congenital cataracts (patients) & $4(26.6 \%)$ & $4(28.5 \%)$ & 0.888 \\
\hline Preexisting amblyopia (eyes) & $4(17.3 \%)$ & $3(14.2 \%)$ & 0.781 \\
\hline
\end{tabular}

Results presented as mean \pm standard deviation (range) or $n(\%)$.

$\mathrm{BCVA}=$ best corrected visual acuity; $\mathrm{IOP}=$ intraocular pressure; $\mathrm{ARMD}=$ age-related macular degeneration; $\mathrm{DR}=$ diabetic retinopathy.

Table 2. Intraoperative and postoperative findings of the patients

\begin{tabular}{|c|c|c|c|}
\hline & Group 1 (viscodissection group) & Group 2 (hydrodissection group) & $p$ value \\
\hline Postoperative BCVA (logMAR) & $0.19 \pm 0.22(0.00-0.70)$ & $0.25 \pm 0.18(0.00-0.70)$ & 0.165 \\
\hline Postoperative IOP (mmHg) & $14.34 \pm 2.28(11-18)$ & $14.66 \pm 2.51(10-19)$ & 0.670 \\
\hline Sulcus fixation IOL implantation (eyes) & $1(4.3 \%)$ & $3(14.2 \%)$ & 0.258 \\
\hline $\begin{array}{l}\text { Plaque formed posterior polar opacity adhered to } \\
\text { posterior capsule (eyes) }\end{array}$ & $8(34.7 \%)$ & $7(33.3 \%)$ & 0.920 \\
\hline
\end{tabular}

Results presented as mean \pm standard deviation (range) or $\mathrm{n}(\%)$.

$\mathrm{BCVA}=$ best corrected visual acuity; $\mathrm{IOP}=$ intraocular pressure; $\mathrm{IOL}=$ intraocular lens.

polar opacities were larger than $4 \mathrm{~mm}$ in soft cataracts, and good results in intracapsular cataract extraction and scleral suturing of the $\mathrm{IOL}$ in hard cataracts.

Ghosh and Kirkby ${ }^{(15)}$ reported that planned pars plana vitrectomy, lensectomy, and posterior chamber IOL implantation can be applied to diminish the rate of posterior capsule rupture in posterior polar cataracts.

Haripriya et al. ${ }^{(16)}$ described a technique in which bimanual microphacoemulsification through two 1.4-mm incisions was performed for posterior polar cataracts. In this technique, the irrigation and aspiration handpieces were interchangeable, enabling the removal of the lens fragments without hydrodissection or nucleus rotation. Nagappa et al. ${ }^{(17)}$ described a modified technique for epinucleus removal in posterior polar cataracts, in which the nucleus was removed, followed by the removal of the epinucleus from the quadrant opposite to the section by aspiration using a phaco probe. Then, hydrodissection was performed to dislodge the subincisional epinucleus, which was aspirated out. Lim and Goh ${ }^{(18)}$ reported a modified epinu- cleus pre-chop technique for dense posterior polar cataracts. In this technique, the anterior epinucleus is first pre-chopped, followed by the removal of the posterior epinucleus and posterior polar plaque.

Hayashi et al. ${ }^{(1)}$ reported that 4 of 10 posterior polar cataract patients with a unilateral opacity exhibited amblyopia. In unilateral cases in which the posterior polar opacity entirely obstructs the pupillary area, the possibility of amblyopia is assumed to be high. In our study also, four patients in group 1 and three in group 2 with unilateral cataract exhibited amblyopia, and postoperative visual acuities were low in these patients.

In conclusion, we can minimize the complications from posterior polar cataract surgeries by being careful throughout the surgery and by using proper techniques. Viscodissection is better for avoiding posterior capsular rupture than hydrodissection. We should also remember that the incidence of preexisting amblyopia is considerable in patients with unilateral posterior polar cataracts, and patients should be warned of it, since the postoperative visual expectancies of patients are generally high. 


\section{REFERENCES}

1. Hayashi K, Hayashi H, Nakao F, Hayashi F. Outcomes of surgery for posterior polar cataract. J Cataract Refract Surg. 2003;29(1):45-9.

2. Kalantan H. Posterior polar cataract: A review. Saudi J Ophthalmol. 2012;26(1):41-9.

3. Das S, Khanna R, Mohiuddin SM, Ramamurthy B. Surgical and visual outcomes for posterior polar cataract. Br J Ophthalmol. 2008;92(11):1476-8.

4. Kumar S, Ram Y, Sukhija J, Severia S. Phacoemulsification in posterior polar cataract: does size of lens opacity affect surgical outcome? Clin and Exp Ophthalmology. 2010; 38(9):857-61.

5. Langwinska-Wosko E, Szulborski K, Broniek-Kowalik K. The complications during phacoemulsification in patients with posterior polar cataract. Klin Oczna. 2011; 113(1-3):16-8.

6. Stanic R, Bucan K, Stanic-Jurasin K, Kovacic Z. Phacoemulsification in eyes with posterior polar cataract. Acta Clin Croat. 2012;51(1):55-8

7. Vasvada AR, Vasavada VA, Raj SM. Approaches to a posterior polar cataract. Saudi $J$ Ophthalmol. 2012:26(1):51-4.

8. Gavriş M, Popa D, Carauş C, Gusho E, Clocotan D, Horvath K, et al. Phacoemulsification in posterior polar cataract. Oftalmologia. 2004;48(4):36-40.

9. Subash M. Posterior polar cataract: minimizing risk of posterior capsule rupture. Eye(Lond). 2007;21(5):674-5. Comment in: Eye (Lond). 2006;20(7):814-6.

10. Siatiri H, Moghimi S. Posterior polar cataract: minimizing risk of posterior capsule rupture Eye(Lond). 2006;20(7):814-6. Comment in: Eye (Lond). 2007;21 (5):674-5; author reply 675.
11. Vasavada AR, Raj SM, Vasvada V, Shrivastav S. Surgical approaches to posterior polar cataract: a review. Eye (Lond). 2012;26(6):761-70.

12. Fine IH, Packer M, Hoffman RS. Management of posterior polar cataract. J Cataract Refract Surg. 2003;29(1):16-9.

13. Allen D, Wood C. Minimizing risk to the capsule during surgery for posterior polar cataract. J Cataract Refract Surg. 2002;28(5):742-4

14. Taskapili M, Gulkilik M, Kocabora MS, Ozsutcu M. Phacoemulsification with viscodissection in posterior polar cataract: minimizing risk of posterior capsule tear. Ann Ophthalmol (Skokie). 2007:39(2):145-9.

15. Ghosh YK, Kirkby GR. Posterior polar cataract surgery- a posterior segment approach. Eye (Lond). 2008;22(6):844-8. Comment in: Eye (Lond). 2009;23(9):1879; author reply 1879.

16. Haripriya A, Aravind S, Vadi K, Natchiar G. Bimanual microphaco for posterior polar cataract. J Cataract Refract Surg. 2006;32(6):914-7.

17. Nagappa S, Das S, Kurian M, Braganza A, Shetty R, Shetty B. Modified technique for epinucleus removal in posterior polar cataract. Ophthalmic Surg Laser Imaging. 2011;42(1):78-80

18. Lim Z, Goh J. Modified epinucleus pre-chop for the dense posterior polar cataract. Ophthalmic Surg Lasers Imaging. 2008;39(2):171-3

19. Vasvada A Singh R. Phacoemulsification in eyes with posterior polar cataract. J Cataract Refract Surg. 1999;25(2):238-45.

20. Osher RH, Yu BC, Koch DD. Posterior polar cataracts: a predisposition to intraoperative posterior capsular rupture. Cataract Refract Surg. 1990;16(2):157-62.

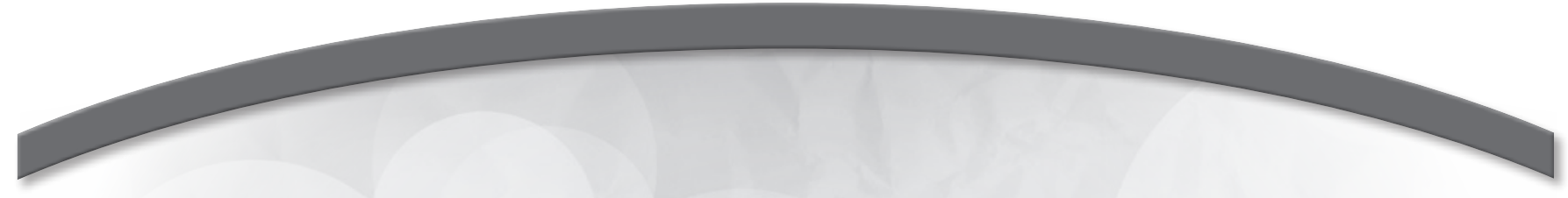

XXXVI Congresso do Hospital São Geraldo

\section{7 a 29 de outubro de 2016}

Hotel Mercure Lourdes

Belo Horizonte - MG

\section{Informações:}

Site: www.hospitalsaogeraldo.com.br/congresso

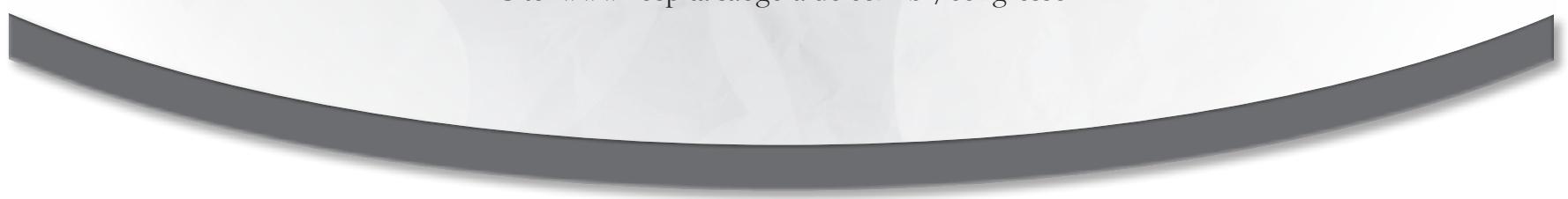

